\title{
INCLUSÃO DE ESTUDANTES COM DEFICIÊNCIA NO ENSINO SUPERIOR: EXIGÊNCIAS DE RECONFIGURAÇÃO DE SABERES, CONCEPÇÕES E PRÁTICAS DOCENTES
}

\author{
INCLUSIÓN DE ESTUDIANTES CON DISCAPACIDAD EN LA ENSEÑANZA \\ SUPERIOR: EXIGENCIAS DE RECONFIGURACIÓN DE SABERES, \\ CONCEPCIONES Y PRÁCTICAS DOCENTES
}

\section{INCLUSION OF DISABLED STUDENTS ON THE HIGHER EDUCATION: DEMANDS OF A RECONFIGURATION OF KNOWLEDGE, CONCEPTIONS AND TEACHING PRACTICES}

\author{
Francisca Geny LUSTOSA ${ }^{1}$ \\ Disneylândia Maria RIBEIRO²
}

RESUMO: O texto reflete sobre o desafio da inclusão de estudantes com deficiência no Ensino Superior, tendo como eixos discussões sobre as políticas de acesso, a percepção discente sobre acessibilidade, a identificação de barreiras e os desafios postos à Universidade e à docência. A pesquisa baseou-se em uma abordagem qualitativa do tipo exploratória. $\mathrm{O}$ corpus da pesquisa se constitui de relatos de sujeitos da UFC, da UECE e da UERN, coletados por meio de entrevistas semiestruturadas, em apreciação, sobre a permanência e o cotidiano vivenciado. As evidências apontam para a superação de concepções padronizadoras de desenvolvimento e aprendizagem, o fortalecimento do princípio do reconhecimento da diferença, a necessidade de instauração de uma nova racionalidade na Educação Superior e da superação de distintas barreiras à participação e à aprendizagem; indica também a necessidade de políticas institucionais intencionais para inclusão, barreiras arquitetônicas como empecilho notório a todos e, ainda, que já existem práticas pedagógicas de professores aliadas nessa construção.

PALAVRAS-CHAVE: Ensino superior. Inclusão. Desafios. Práticas pedagógicas.

RESUMEN: El texto reflexiona sobre el desafio de incluir a los estudiantes con discapacidades en la enseñanza superior, teniendo como ejes de debates las políticas de inclusión, la percepción del estudiante sobre la inclusión, identificación de entrabes y los desafios planteados a la universidad y enseñanza. La investigación se basó en un enfoque exploratorio cualitativo. El corpus de la investigación consta de informes de sujetos de UFC, UECE y UERN, recogidos a través de entrevistas semiestructuradas, en análisis, sobre la permanencia y el cotidiano experimentado. La investigación trae como principales resultados

${ }^{1}$ Universidade Federal do Ceará (UFC), Fortaleza - CE - Brasil. Professora Adjunta do Departamento de Estudos Especializados da Faculdade de Educação (DEE/FACED). Membro do Observatório de Internacional de Inclusão, Interculturalidade e Inovação Pedagógica (OIIIIPe). ORCID: https://orcid.org/0000-0002-6143-9549. E-mail: franciscageny@yahoo.com.br

${ }^{2}$ Universidade do Estado do Rio Grande do Norte (UERN), Pau dos Ferros - RN - Brasil. Professora Adjunto do Departamento de Educação, do CAMEAM/UERN. Pesquisadora Institucional do Núcleo de Estudos em Educação (NEEd/CAMEAM/UERN). Doutoranda em Educação (UFC). ORCID: https://orcid.org/0000-00031411-5880. E-mail: d-landia@hotmail.com 
la superación de las concepciones comunes de desarrollo y aprendizaje, el fortalecimiento del principio de reconocimiento de las diferencias, la necesidad de una nueva racionalidad en la enseñanza superior y la superación de diferentes entrabes para la participación y el aprendizaje. Los resultados indican también la necesidad de políticas institucionales intencionales para la inclusión, resolución de problemas arquitectónicos que son un obstáculo relevante para todos. Por fin, la investigación identificó que ya existen aliados pedagógicos en esta construcción.

PALABRAS CLAVE: Enseñanza superior. Inclusión. Desafios. Prácticas docentes.

ABSTRACT: The text discusses about the challenge of including disabled students on the higher education system, choosing as main topics the access policies, the perception of students about accessibility and the identification of barriers and challenges Universities and Professors face. The research was based on a qualitative exploratory approach. The research corpus consists of reports by subjects of three public institutions: UFC, UECE and UERN, it was collected through semi-structured interviews, under analysis about the permanence of subjects and their daily life experienced there in the places they work. Evidences show the overcoming of standard conceptions about development and learning, the strengthen of the understanding of the differences, the need of establishing a new rationality in the higher education system and the overcoming of several barriers to the participation and to the learning, as well as it indicates too the demand of institutional policies to social inclusion, architectural issues as a obstacle for all of them, and that there are some pedagogical practices that corroborate to that situation.

KEYWORDS: Higher education. Inclusion. Challenges. Teaching practices.

\section{Introdução}

O presente texto discute a inclusão de estudantes com deficiência no ensino superior, considerando as políticas públicas de acesso, os desafios e as conquistas advindas às instituições de ensino e também aos sujeitos de direito. Compreendemos que tais informações explicitam, em muito, as barreiras ainda enfrentadas por esse público-alvo, todavia, por seu turno, apresentam também os principais alvos-metas de transformação necessárias a se implementar nas instituições de ensino superior (IES).

$\mathrm{O}$ estudo aqui empreendido reflete sobre as ideias atinentes à área quanto à inclusão de sujeitos com deficiência no Ensino Superior. Portanto, nos posicionamos que é necessário tensionar a política de inclusão desses estudantes nas IES e, também, compreender e acompanhar as implicações desse processo na docência universitária.

É notório que a presença de estudantes com deficiência em IES potencializa a consolidação dos direitos dos sujeitos, as lutas empreendidas e os avanços conseguidos, mas revela também conflitos inerentes à prática institucional e pedagógica, que manifesta nas práticas avaliativas em curso, notadamente, grandes impedimentos, por serem caracterizadas, 
predominantemente, como classificatórias e seletivas, enquanto os discursos da inclusão vão requerer dos docentes a produção de subjetividades com vistas à solidariedade, a cooperação/colaboração, ao acolhimento.

No ensino superior localizamos, em particular, um conflito gerado pela perspectiva seletiva e excludente ditada pela secularidade desta instituição e seus objetivos de formação esperados pela sociedade. As fragilidades docentes para lidar com a diferença se evidenciam no ensino quanto às práticas pedagógicas e formas de apoio, mas também tem no processo avaliativo e em suas formas tradicionais de realização um desafio específico.

A docência no ensino superior deve ser o objeto de investigação das instituições e seus gestores, em virtude da importância que tem para os pilares do ensino, da pesquisa e da extensão, envolvendo as nuances dessa atuação profissional nos campos político, pedagógico e sociocultural. Algumas indagações são provocativas à reflexão: o que um estudante com deficiência desperta nos docentes das IES? E, ainda, o que potencializa a docência universitária para a inclusão?

O docente do ensino superior ocupa-se e cumpre uma extensa programação profissional, que ultrapassa as atividades de elaborar e de ministrar aulas. No dia a dia, no cotidiano da universidade, os professores têm como responsabilidade a participação e coordenação de projetos de pesquisa, preparação de relatórios, orientações de trabalhos de conclusão de curso, produção de artigos científicos e outras atividades, sustentando o tripé do ensino, da pesquisa e da extensão. Exercer essas atividades profissionais exige tempo, energia e dedicação e, ainda, sob sua responsabilidade, a formação do pesquisador, que é realizada nos cursos de pós-graduação stricto sensu.

\section{Aspectos metodológicos}

A pesquisa baseou-se em uma abordagem qualitativa do tipo exploratória. Como campo empírico para discussão, trazemos as reflexões teóricas que fundamentam o estudo, e amparam a análise dos dados relatos de discentes com deficiências, de forma ilustrativa, em apreciação ao acesso, permanência e ao cotidiano vivenciado.

Assim, utilizamos, neste texto, entrevistas procedidas a estudantes com deficiência, sendo: 7 da Universidade Federal do Ceará $^{3} /$ UFC, 6 da Faculdade de Educação e 1 do curso

${ }^{3}$ A UFC tem cerca de 450 estudantes com deficiências, sendo: 100 deficientes visuais ou cegos, 85 com altas habilidades, 42 com surdez, 107 com deficiência física, 13 com DI, 6 com autismo, 1 com síndrome de Rett, 6 com deficiência múltipla, 1 com transtorno degenerativo (RELATÓRIO DE ALUNOS COM NECESSIDADES ESPECIAIS, STI/UFC, Emitido em 22/8/2019). 
de Ciências Biológicas); 1 da Universidade Estadual do Ceará/UECE (Curso de Pedagogia); 2 da Universidade do Estado do Rio Grande do Norte/UERN (1 ex-aluno do Curso de Licenciatura em Música e outro do Curso de Enfermagem). Articulamos, ainda, entrevista com a servidora da UFC que atua como Agente de Inclusão na instituição.

As narrativas desses sujeitos podem nos dizer muito sobre os desafios enfrentados, ao tempo que podem validar (ou não!) as estratégias institucionais implementadas e subsidiar, de forma mais comprometida, essa ruptura paradigmática que exige dos professores a reconfiguração de saberes, concepções e práticas no contexto universitário.

\section{Desafios à inclusão na Educação Superior: identificando e superando barreiras}

Estatísticas oficiais ${ }^{4}$ apresentam a expansão quantitativa das matrículas de estudantes com deficiência na Educação Superior. Essa ampliação do número de instituições, cursos e vagas contribui para a significação da inclusão nesse nível/etapa da educação e da formação dos sujeitos sociais.

Os dados censitários, via de regra, são enaltecidos como indicadores de avanços na inclusão desses estudantes, porém, a (re)organização dos sistemas de ensino ainda está aquém do que é referendado sociopoliticamente para uma instituição democrática, que se comprometa com igualdade de oportunidades a todos os sujeitos.

Convém ressaltar que a presença de tais estudantes nas IES favorece a criação de novas demandas e, ao mesmo tempo, revelam antigos problemas antes não resolvidos ou que não tiveram a devida atenção, historicamente.

Defendemos que deve haver o cuidado, em relação aos estudantes público-alvo da Educação Especial, para não penalizá-los ou vitimá-los, duplamente, pela falta de adequação institucional. Eles foram historicamente excluídos - pela forma de exclusão no exterior dos sistemas de ensino. Não podemos reproduzir formas de exclusão, agora, no interior do sistema (configurando uma exclusão camuflada ou pseudoinclusão).

Assim, se faz necessário agirmos, prioritariamente, em função de superar algumas barreiras, entre as quais destacamos: i. A superação de concepções padronizadoras de

\footnotetext{
${ }^{4}$ Informações do Ministério da Educação (MEC), divulgadas em seu site, indicam a evolução do número de Matrículas em Cursos de Graduação de Alunos com Deficiência, Transtornos Globais do Desenvolvimento ou Altas Habilidades/Superdotação (2009-2017), expressando um quantitativo de 20.530 estudantes em 2009 para o expressivo número de $38.272 \mathrm{em} 2017$. Desse quantitativo, temos um dado que merece ressalva, pois, quanto às esferas de ensino, temos mais estudantes matriculados em instituições privadas do que na pública. (Censo da educação superior, 2017). Divulgação dos principais resultados. Diretoria de Estatísticas Educacionais Deed/MEC-INEP.Brasília-DF. Setembro de 2018. Disponível em: http://portal.mec.gov.br/docman/setembro2018-pdf/97041-apresentac-a-o-censo-superior-u-ltimo/file. Acesso em: 26 set. 2019.
} 
desenvolvimento e aprendizagem dos sujeitos; ii. O não reconhecimento da diferença como marca fundante da humanidade; iii. A superação de barreiras - arquitetônicas, atitudinais ${ }^{5}$,

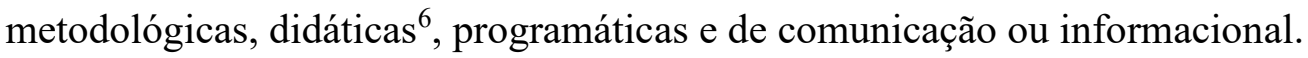

Uma nova racionalidade deve ser pautada na educação superior. As IES precisam agir rápido, em função da superação, retirada e/ou minimização de barreiras ${ }^{7}$. Isso requer iniciativas institucionais, cobradas na esfera do direito, principalmente se estivermos na seara de uma IES pública: acessibilidade é Lei e deve ser atendida/cumprida; é direito subjetivo dos sujeitos! Todavia, parece que tal compreensão, não é, ainda, a dos gestores institucionais.

As perspectivas educacionais acerca da inclusão em educação ganham voluptuosidade e os professores de instituições de ensino superior sabem disso, ou seja, não estão alheios a tais normativas, inclusive, em função do mais alto nível de formação intelectual, discernimento e pensamento crítico que possuem. Todavia, um fato é intrigante: esse nível de conhecimento, titulação e do pensamento crítico não se revela diretamente em mais "poder" de inclusão.

Outro aspecto peculiar é o fato de que o conhecimento de todos os educadores desse nível de ensino já abarca, no plano das ideias, a defesa pedagógica sobre a reorganização de ambientes de aprendizagem e como mobilizá-la; as defesas quanto à necessária diversificação de metodologias de ensino para favorecer a aprendizagem dos sujeitos e seus ritmos diferenciados; a importância de adoção de técnicas de trabalho cooperativo e perspectivas de aprendizagem colaborativa, em rede; a inserção de aprendizagem por meio da resolução de problemas e de conflitos sociocognitivos; além do reconhecimento do protagonismo e da mediação pedagógica como ação privilegiada para o processo de ensino e de aprendizagem, também da compreensão da importância da cultura e do social para o desenvolvimento e aprendizagem dos sujeitos, corpus de ideias interacionistas, etc.

Tais conhecimentos poderiam se reverter em "soluções"; surpreendentemente, nesse caso, não é o que acontece. Igualmente aos demais professores da Educação Básica, o que ecoa são argumentos da ordem: "não sabemos o que fazer; não fui formado para ensinar estudantes com deficiência!”. O que pensar sobre essa circunstância?

\footnotetext{
${ }^{5}$ Lima e Tavares (2008) identificam e analisam a taxonomia das barreiras atitudinais.

${ }^{6}$ Lustosa (2009) apresenta e caracteriza o conceito de barreiras didáticas.

7 Incluímos aqui as adaptações razoáveis, presente como obrigação no cumprimento da legislação. Para esclarecer: "[...] as adaptações razoáveis podem ser solicitadas não somente no âmbito do ensino público, como também nas entidades particulares de ensino, não podendo ser recusadas injustificadamente, sob pena de se considerar discriminação em razão da deficiência”. (FERREIRA, 2019, p. 132). Disponível em: http://www.repositorio.ufc.br/bitstream/riufc/44448/1/2019_dis_rcgslferreira.pdf. Acesso em: set. 2019. Referido direito é assegurado pela Lei Brasileira de Inclusão (LBI n ${ }^{\circ} 13.146 / 2015$, em seu artigo $4^{\circ}, \S^{\circ}$ ) e pela Convenção Internacional sobre os Direitos da Pessoa com Deficiência (CDPCD, artigo $2^{\circ}$ ).
} 


\section{Desafios postos à Universidade e aos sujeitos com deficiência: a percepção quanto à acessibilidade e as barreiras para 0 atendimento às diferenças no Ensino Superior}

A preocupação com um processo educacional que reconheça a inclusão como princípio educativo, que respeite a diversidade dos sujeitos e os distintos contextos socioculturais dos estudantes, tem sido fundamento de narrativas contemporâneas, com amparo em argumentos éticos, normativos e pedagógicos.

Pesquisas na temática (SANTOS et al., 2018; PIECZKOWSKI, 2016) apontam para a necessidade de uma nova organização institucional para atender ao paradigma da inclusão - o que exige identificar e enfrentar os desafios inerentes a uma educação aberta à diversidade. Quando esse processo é deflagrado, intencionalmente pensado, planejadamente executado e lucidamente avaliado, entra-se num processo de ascese organizacional nas dimensões política, ideológica, pedagógica, que vai se refletir em novas práticas, na construção de valores e concepções, renovações estruturais, etc...

Por sua vez, o conceito de inclusão que nos serve de parâmetro é entendido como resultado de um conjunto de culturas, políticas e práticas que resultam em processos de efetiva participação e protagonismo dos sujeitos, cujas implicações se reverberam na (re)construção dos espaços e dispositivos includentes (de políticas institucionais, principalmente!), conforme a perspectiva apontada por Booth e Ainscow (2012).

Nesse cenário, a acessibilidade ocupa um papel importante em uma cultura inclusiva, o que requer tomá-la em uma compreensão mais ampla. Para as autoras Maciel e Anache (2017), é preciso que as instituições decidam por mudanças estruturais e políticas para que essas pessoas possam adentrar em seus espaços - isso significa a criação de formas de acesso por editais ou quotas específicas, produção de editais acessíveis com tradução para Braile e LIBRAS, disponibilização de apoio na realização de exames, ampliação de tempo de prova, etc, e, seguidamente, que suas necessidades sejam atendidas para permanência ${ }^{8}$.

A Lei de Acessibilidade (Lei n. 10.098) estabelece quatro categorias de barreiras: arquitetônicas urbanisticas, arquitetônicas na edificação, arquitetônicas nos transportes, nas comunicações. Na educação, temos também a acessibilidade ao currículo, que se materializa nas práticas pedagógicas e nas formas de apoio para acesso ao conhecimento.

${ }^{8}$ Como exemplos, citamos: a disponibilização de mobiliários específicos, de profissionais de apoio, de ledores, textos em áudio ou ampliados, intérpretes, disponibilização prévia de materiais escritos, textos digitados ou impressos em Braille, dentre outros apoios e/ou recursos, além de adaptações de espaços, tempo de realização de avaliações ou de instrumentais avaliativos e outras flexibilizações, em reconhecimento da necessidade dos estudantes. 
Em um determinado plano, acessibilidade passa pela disponibilidade de intérpretes de Libras (Decreto $\mathrm{n}^{0} 5.626 / 2005$ ), a oferta de tecnologia assistiva e comunicacional (Lei $\mathrm{n}^{\mathrm{o}}$ 13.146/2015; Decreto $n^{0}$ 7.612/2011), tanto quanto pela adequação/adaptação do espaço físico, de modo que responda aos princípios básicos da ergonomia e da própria acessibilidade física (NBR 9050).

Tomando a UFC como exemplo, é destacável a Secretaria de Acessibilidade UFC Inclui $^{9}$, implantada como fruto de uma política pública de fomento às universidades federais ${ }^{10}$. Essa secretaria assume-se como instância administrativa para viabilizar políticas e ações para o desenvolvimento de uma cultura universitária inclusiva e acessível. Dentre os serviços, a Divisão de Tradutores e Intérpretes de Língua de Sinais (DIVITILS), com 12 profissionais nessa especialidade; conta também com equipamentos específicos de apoio aos estudantes cegos para as leituras e demais atividades acadêmicas, além de bibliotecas com acessibilidade informacional, produção de materiais e programas computacionais. Outras ações importantes se referem ao acesso por cotas para pessoas com deficiência (conforme estabelece a Lei 13.409/2016, na UFC desde o SISU 2018) e a criação dos Agentes de Inclusão ${ }^{11}$.

Na UERN, de esfera estadual, existe a Diretoria de Políticas e Ações Inclusivas $(\mathrm{DAIN})^{12}$, um órgão de apoio à inclusão educacional vinculado administrativa, técnica e pedagogicamente à Pró-Reitoria de Ensino de Graduação (PROEG), que oferece suporte material, humano e pedagógico aos discentes com deficiência nas atividades socioeducacionais promovidas em âmbito institucional. No que se refere ao acesso aos cursos de graduação, a UERN adota o sistema de cotas por meio do Sistema de Seleção Unificada (SISU) e o Processo Seletivo Vocacionado (PSV/Vestibular), em cumprimento à Lei Estadual $\mathrm{n}^{\mathrm{o}} 9.696$, de 25 de fevereiro de 2013, que dispõe sobre a reserva de $5 \%$ das vagas para pessoas com deficiência.

9 Criada em agosto de 2010. Mais informações das ações realizadas por esse equipamento, ver https://acessibilidade.ufc.br/agentes-de-acessibilidade-da-unidades-academicas/.

10 Em atendimento ao Decreto $\mathrm{n}^{\mathrm{o}}$ 5.296/2004. "De 2005 a 2010, o programa Incluir lançou editais com a finalidade de apoiar projetos de criação ou reestruturação desses núcleos nas IFES. No primeiro edital, em 2005, foram aprovados 13 projetos de inclusão nas instituições públicas de educação superior. [...] No total foram 199 projetos de inclusão na educação superior aprovados pelos editais do Programa Incluir." (MACIEL; ANACHE, 2017, p. 83).

11 Política interna da UFC de apoio aos estudantes com deficiências. O serviço conta com profissionais da própria instituição (técnicos administrativos e/ou docentes), distribuídos em 17 unidades, sendo 4 nos campus do interior.

${ }^{12}$ Em 18 de abril de 2008, a UERN criou o Departamento de Apoio à Inclusão (DAIN), por meio da Resolução $n^{\circ}$ 2/2008 do Conselho Universitário - CONSUNI. Em 2010, passa a ser denominada Diretoria de Políticas e Ações Inclusivas (DAIN), por meio da Resolução n ${ }^{\circ}$ 31/2010-CD. 
$\mathrm{Na}$ investigação que realizamos, os resultados evidenciam que, dentre as dificuldades enfrentadas pelos sujeitos com deficiência nessas instituições, as barreiras arquitetônicas são bastante enfatizadas, o que demonstra, ainda, a carência das referidas universidades nesse aspecto. Em todos os relatos encontramos menções a elas:

Eu ando no Campus do Pici na UFC, é horrivel lá... Igualmente no Centro de Humanidades (CH3), PREX, PRAE, em nenhum canto eu encontrei acessibilidade. (Curso de Pedagogia, estudante com deficiência física).

O que me incomoda mais é a questão do elevador que não funciona há mais de 4 anos. (Curso de Pedagogia, estudante com deficiência).

Sentia muita dificuldade para subir as escadas, porque as aulas de enfermagem eram no $1^{\circ}$ andar, tinha que subir as escadas, já cheguei até uma vez quase cair lá. (Ex-aluno do Curso de Enfermagem/UERN, estudante com deficiência visual).

Esses depoimentos nos levam a inferir que a acessibilidade arquitetônica não parece ser prioridade dos gestores - governos, reitores, pró-reitores, diretores, chefes e coordenadores de cursos, que não encaram a inclusão do estudante com deficiência como assunto de gestão e de política universitária.

É necessário, por lei, que os prédios tenham além de rampas, sinalização para indicar banheiros e demais espaços, além da necessidade de sinalização tátil de piso, para proteção, orientação e mobilidade, especialmente para pessoas com deficiência visual, ainda que, como já sabemos, beneficie a todos.

Em outro relato de estudante, temos a enunciação de desrespeito até diante da garantia da lei, como mostra a seguinte argumentação feita:

De que adianta ter uma rampa, se estacionam na frente? De que adianta ter um banheiro acessivel, se ele é utilizado por quem não tem deficiência ou é feito a guarda de material de limpeza, como depósito? (Curso de Pedagogia da UFC, estudante com deficiência física).

Nesse caso, ocorre a inobservância do Decreto $n^{0}$ 5.296, de 2 de dezembro de 2004, que em seu Art. 24 afirma: “Os estabelecimentos de ensino de qualquer nível, etapa ou modalidade, públicos ou privados, proporcionarão condições de acesso e utilização de todos os seus ambientes ou compartimentos para pessoas portadoras de deficiência ou com mobilidade reduzida [...] (BRASIL, 2004).

Nessa perspectiva, Ribeiro (2018) certifica que as condições físicas de funcionamento dos cursos de graduação podem afetar irremediavelmente as questões de acesso, permanência, participação e aprendizagem dos estudantes. Segundo a pesquisadora, as barreiras 
arquitetônicas se configuram um processo de restrição e exclusão educacional, na medida em que prejudicam e impedem o exercício de direitos e das liberdades fundamentais da pessoa com deficiência.

Foram mencionadas também, nas entrevistas, as barreiras de ordem comunicacional, atitudinal e instrumental:

Com relação às barreiras atitudinais já começam na falta de reflexão e do debate na faculdade [...]. Quando se fala de Inclusão aqui é em eventos pontuais e eventos que são propícios para a área, organizados por professores da área. (Curso de Pedagogia da UFC, atualmente cursando o Mestrado, estudante com deficiência).

Não tem informações em Braille nas paredes e nem nas salas de aula, mesmo tendo um aluno cego que está no $2^{\circ}$ semestre. (Curso de Pedagogia da UFC, estudante sem deficiência).

Na sala, por exemplo, não existe acessibilidade de recurso de tecnologia assistiva; nesse campo realmente não existe acessibilidades. (Ex-aluno curso de Música/PARFOR/UERN, estudante com deficiência visual).

As referidas barreiras restringem a autonomia e a participação nas diversas atividades realizadas naquele ambiente, pela falta de equiparação de oportunidades educacionais. As consequências emocionais e comportamentais desses processos podem ser observadas nas narrativas que se seguem:

Eu pensei em desistir do curso porque eu estou cansada de ter os meus direitos desrespeitados. É por isso que acontece a evasão do estudante. A minha luta é diária. Eu tenho que brigar com o mundo inteiro pra que eles me respeitem, pra que haja alguma empatia. (Curso de Pedagogia, estudante com deficiência).

O que precisa primeiro é sensibilidade em incluir a pessoa, em seguida acessibilidade arquitetônica e curricular. Eu quase desisti da faculdade logo no inicio do $2^{\circ}$ semestre. Hoje a universidade disponibiliza um motorista que me pega em casa e me leva às aulas e para o Atendimento Educacional Especializado, no projeto de extensão da UFC e tenho uma auxiliar para o restaurante universitário, quando fico para almoçar lá... Mas, no começo foi muito difícil.

Notório que os discentes com deficiência manifestam uma percepção pessimista com relação à possibilidade de mudança e superação das barreiras que se interpõem aos seus percursos formativos. Eles sinalizam, dentre outras questões, o desrespeito às suas idiossincrasias e denunciam processos e práticas que dificultam a efetivação de uma política universitária que satisfaça as necessidades básicas de aprendizagem, participação e exercício da cidadania. 
Em contrapartida, identificamos algumas reivindicações com relação aos caminhos que a universidade poderia seguir:

Precisamos ser ouvidos e precisamos que nossas necessidades sejam atendidas. Temos o direito a uma educação presencial, que está incluída no nosso direito de ir e vir e de ser feliz. [...] A minha/nossa presença na Faced vai fazê-la mudar na medida em que falhas forem sendo apontadas $e$ melhorias forem sendo sugeridas. (Curso de Pedagogia da UFC, estudante com deficiência física)

Primeiramente, ouvir a demanda das pessoas com deficiência, dar voz. Posteriormente, ampliar os investimentos em infraestrutura, o que inclui a compra de equipamentos e treinamento de professores, além de intérpretes de libras disponíveis em todos os cursos para os alunos surdos. (Curso de Pedagogia da UFC, estudante com deficiência).

Diante dessa conjuntura, deduzimos que as ações e as políticas de inclusão desenvolvidas no âmbito da UFC, da UECE e da UERN são relevantes na medida em que ampliam o acesso. Todavia, sublinhamos que ainda temos um longo caminho a percorrer na construção de culturas, políticas e práticas que se materializem num trabalho efetivo de remoção às barreiras que obstaculizam a aprendizagem e o desenvolvimento da autonomia, independência e empoderamento do estudante com deficiência. É preciso oferecer suporte material, humano e pedagógico aos estudantes com deficiência.

\section{Práticas da inclusão em educação: desafios à docência no Ensino Superior}

As discussões em tela nos mostram quão necessárias são as mudanças no contexto da universidade, “[...] o que implica a superação de barreiras principais: nas atitudes e formas de compreender e lidar com as diferenças; nas práticas pedagógicas, propriamente ditas, na superação das barreiras didáticas.” (LUSTOSA, 2009, p. 145).

O relato ${ }^{13}$ de um dos estudantes da UFC com deficiência visual descortina a expressão dessa barreira na prática docente, ao tempo em que também nos mostra que existem possibilidades de superação:

Logo quando entrei na universidade tive dificuldade com o material disponibilizado por um professor que, a princípio, não colocava vídeos acessiveis. Na primeira aula, o professor passou um vídeo em que teria que assistir e fazer um resumo e enviá-lo por e-mail. Quando fui realizar a atividade em casa, era um vídeo que tinha apenas imagens e um fundo musical; pedi ajuda à agente de inclusão e fiz a atividade; na segunda vez

${ }^{13}$ Relato proferido em evento "Vivências acadêmicas de alunos com deficiência visual do Curso de Pedagogia da UFC, 2019”. Disponível em: https://youtu.be/UpE8HMmbSQw. Acesso em: set. 2019.

RIAEE - Revista Ibero-Americana de Estudos em Educação Araraquara, v. 15, n. esp. 2, p. 1523-1537, ago. 2020. e-ISSN: $1982-5587$. 
outro vídeo, agora em inglês e legendado. Então, eu fiz uma versão em Braille e entreguei ao professor na sala de aula: Professor é um texto escrito em Braille, uma versão que eu fiz especialmente para o senhor, para o senhor ler em voz alta, fazer a correção e dar minha nota [...]. Após esse episódio, o professor mudou completamente sua postura, abrindo-se às minhas necessidades e buscando efetivamente me incluir na dinâmica da turma. [...] O professor passou a ser mais atento e mais sensivel e foi um prazer ter sido seu aluno. "Quando crescer quero ser como ele". (Curso de Pedagogia da UFC, estudante com deficiência visual).

Em conformidade com essa acepção, o ato de ensinar deve ser transformado profundamente para viabilizar a participação de todos os estudantes, sem descuidar, entretanto, das diferenças e identidades individuais.

Com o advento da perspectiva da inclusão em educação, o conceito de acessibilidade também se volta à reconfiguração das práticas pedagógicas, dos recursos materiais e dos arranjos dos espaços e (re)organização dos tempos didáticos, visando acessibilizar o currículo escolar, por meio de metodologias diversificadas de ensino (procedimentos, estratégias e recursos).

Nesse horizonte, mencionamos os princípios do Desenho Universal para a Aprendizagem $\left(\mathrm{DUA}^{14}\right)$ como possibilidade de tornar acessível o currículo geral a todos os estudantes, por meio de práticas pedagógicas diversificadas e comprometidas com o desenvolvimento cognitivo, psicomotor, afetivo, social e cultural dos sujeitos. Segundo Nunes e Madureira (2015, p. 140):

Esta abordagem, designada DUA, considera que para promover a aprendizagem é importante que o professor tenha em consideração as redes afetivas, as redes de reconhecimento e as redes estratégicas. O que significa a importância de o docente organizar a intervenção pedagógica equacionando sistematicamente estratégias diversificadas, de modo a assegurar que todos os alunos se sentem motivados para aprender, que todos têm facilidade em aceder e compreender os conteúdos de ensino e, por último, que todos vivenciam experiências de acordo com as suas necessidades e possibilidades de expressão.

Tendo por base os constructos teóricos relacionados à Pedagogia da Diferença e ao DUA passamos à reflexão das práticas pedagógicas dos professores, propriamente ditas: o que assinalam as narrativas dos estudantes com deficiência?

Uma parte dos estudantes com deficiência mencionou algumas ações realizadas por professores para atender as demandas de inclusão em sala de aula, adaptações que envolvem a

14 CAST. Universal design for learning guidelines version 2.2. 2018. Disponível em: http://udlguidelines.cast.org/?utm_medium=web\&utm_campagin=none\&utm_source=cast-home. Acesso em: 07 fev. 2019. 
organização do mobiliário, a troca de sala de aula do $1^{\circ}$ andar para o térreo e adequações de ordem comunicacional:

A maioria [dos professores] é bastante compreensiva. Alguns poderiam ter um pouco mais de empatia, como o professor $x$, que decidiu nos transferir para outra sala [mais acessivel], depois de ter visto a minha dificuldade ao caminhar, o que me ajudou muito, pois chego rapidamente à sala de aula. (Curso de Ciências Biológicas da UFC, estudante com deficiência física com uso de cadeira de rodas).

Todos os professores fazem pequenas adaptações que me fazem sentir mais incluida, seja colocando legenda no filme, tentando falar um pouco mais alto ou falar olhando para mim. São pequenas coisas, mas me fazem sentir mais acolhida. (Ex-aluna do Curso de Enfermagem/UERN estudante com deficiência visual).

Outras narrativas sugerem a presença de barreiras didáticas:

A questão que tinha mais dificuldade eram as aulas práticas, só nas aulas práticas de anatomia [...]. A professora de anatomia aplicava métodos que eu não conseguia acompanhar. [...] ela usava o laser, eu não conseguia ver o que ela estava mostrando, não conseguia ver o que ela estava explicando, ela ficava sentada com o laser mostrando no quadro... E eu já tinha avisado aos professores do departamento e ela continuava fazendo isso. (Ex-aluno do Curso de Enfermagem/UERN, estudante com deficiência visual).

Eu digo que talvez não seja nem uma dificuldade minha, seja mais uma falha metodológica do professor que deveria fazer as atividades, me mostrar e me dá um pequeno tempo a mais para que pudesse desenvolver a atividade e junto com a turma fazer. (Ex-aluno do Curso de Música/PARFOR/UERN, estudante com deficiência visual).

Parece-nos que a dificuldade em lidar pedagogicamente com as diferenças é uma realidade presente na Educação Superior. Os fundamentos pedagógicos que preconizam o atendimento às diferenças de estilos, ritmos e modos singulares de aprendizagem, bem como aos interesses e distintas formas de expressão dos sujeitos não estão consolidados em algumas práticas docentes.

Rodrigues (2004) nos oferece algumas hipóteses para analisarmos as barreiras didáticas presentes nas práticas pedagógicas, também relatadas pelos discentes com deficiência que aqui expomos. Segundo o autor, algumas concepções e dilemas interferem no processo de mobilização dos professores para adotarem práticas inclusivas, as quais: i. A universidade reflete pouco sobre "pedagogia, metodologias de ensino e sobre as causas de (in)sucesso dos seus estudantes; ii. Os professores não percebem que o "processo de ensinoaprendizagem é um processo repartido, interativo e de responsabilidade mútua do professor e do aluno"; iii. O fato de o professor considerar que o programa de sua disciplina deve ser 
seguido sem alteração. (RODRIGUES, 2004, p. 3). Referidos fatos impedem o atendimento às diferenças no âmbito universitário, em grande parte, se refletem no ensino e na aprendizagem, mutuamente.

\section{Considerações finais}

O cenário de crescente aumento do ingresso de estudantes com deficiência em IES nos últimos anos, bem como a presença concreta desse estudante nas salas de aula, pode vir a permitir implicações positivas sobre discursos e práticas inclusivas.

Assim sendo, pontuamos alguns aspectos que indicaram a necessidade de políticas institucionais intencionais para inclusão e para a eliminação de barreiras arquitetônicas, visto que estas se apresentam como notório empecilho a todos. Importante também destacar que, em meio às lacunas, já existem práticas pedagógicas de professores aliadas nessa construção, que podem servir de referentes para a mobilização, cada vez maior, de atitudes e de princípios inclusivos.

A literatura, por sua vez, tem enfatizado a importância de se desenvolver práticas de colaboração e trabalho em equipe entre professores e estudantes, aspecto muitas vezes relegado ao plano utópico, principalmente, na docência universitária. Do mesmo modo, é precípua a necessidade do professor se colocar como mediador e possibilitador de crescimento geral dos seus estudantes.

O panorama realçado pelas pesquisas indica a imprescindibilidade de edificarmos uma compreensão inovadora dos processos de ensino e de aprendizagem na Educação Superior. O professor/pesquisador precisa, portanto, encarar o planejamento pedagógico e a ação didática de forma mais flexível, mobilizando esforço e energia intelectual na elaboração de métodos de ensino inovadores e diversificados, capazes de engajar, notadamente, os estudantes mais desafiadores.

Diante das discussões suscitadas reafirmamos a necessidade de construção de saberes e de novas práticas pedagógicas no âmbito do Ensino Superior [...]. Em Educação, esse processo de inclusão, que é sempre sem fim, envolve muitas mudanças objetivando aumentar a aprendizagem e participação plena de todos. (SANTOS; FONSECA, 2013, p. 132). Salientamos que a inclusão, da forma como a compreendemos, é um processo dinâmico, mutável, rico e possível de ser atingido, enredado em valores, políticas e práticas de justiça social e educacional. 


\section{REFERÊNCIAS}

BOOTH, Tony; AINSCOW, Mel. Index para a inclusão: desenvolvendo a aprendizagem e a participação nas escolas. Tradução de Mônica Pereira dos Santos e João Batista Esteves. 3. ed. Bristol: CSIE, 2012.

BRASIL. Decreto Federal n. 5.296, de 2 de dezembro de 2004. Disponível em: http://www.planalto.gov.br/ccivil_03/_ato2004-2006/2004/decreto/d5296.htm. Acesso em: 06 set. 2017.

BRASIL. Decreto Federal n. 5.626, de 22 de dezembro de 2005. Disponível em: http://www.planalto.gov.br/ccivil_03/_ato2004-2006/2005/decreto/d5626.htm. Acesso em: 13 jun. 2019.

BRASIL. Decreto Federal n. 7.612, de 17 de novembro de 2011. Disponível em: http://www.planalto.gov.br/ccivil_03/_Ato2011-2014/2011/Decreto/D7612.htm. Acesso em: 08 de maio de 2019.

BRASIL. Lei 13.146, de 6 de julho de 2015. Institui a Lei Brasileira de Inclusão da Pessoa com Deficiência (Estatuto da Pessoa com Deficiência), Brasília, 2015.

CAST. Universal design for learning guidelines version 2.2. 2018. Disponível em: $\mathrm{http}$ //udlguidelines.cast.org/?utm_medium $=$ web\&utm_campagin=none\&utm_source $=$ casthome. Acesso em: 07 fev. 2019.

FERREIRA, Rebeca Costa Gadelha da Silveira Lopes. As adaptações razoáveis no modelo de educação inclusiva para estudantes surdos. 2019. 207 f. Dissertação (Mestrado em Direito) - Universidade Federal do Ceará, Fortaleza, 2019.

LUSTOSA, Francisca Geny. Inclusão, o olhar que ensina: o movimento da mudança e a transformação das práticas pedagógicas no contexto de uma pesquisa-ação colaborativa. 2009. 295 f. Tese (Doutorado em Educação) - Universidade Federal do Ceará, Fortaleza, 2009.

MACIEL, Carina Elisabeth. ANACHE, Alexandra Ayach. A permanência de estudantes com deficiência nas universidades brasileiras. Educar em Revista, Curitiba, Brasil, v. 33, n. especial 3, p. 71-86, dez. 2017. Disponível em: http://www.scielo.br/pdf/er/nspe.3/0104-4060er-03-71.pdf. Acesso em: 29 set. 2019.

NUNES, Clarisse; MADUREIRA, Isabel. Desenho Universal para a Aprendizagem: Construindo práticas pedagógicas inclusivas. Da Investigação às Práticas, Portugal, v. 5, n. 2, p. 126-143, set. 2015. Disponível em: http://www.scielo.mec.pt/pdf/inp/v5n2/v5n2a08.pdf. Acesso em: 09 abr. 2019.

PIECZKOWSKI, Tania Mara Zancanaro. Avaliação da aprendizagem de estudantes com deficiência na educação superior. Rev. Bras. Estud. Pedagog. vol. 97, nº. 247. Brasília, set./dez. 2016. Disponível em:

http://www.scielo.br/scielo.php?script=sci_arttext\&pid=S2176-66812016000300583. Acesso em: 29 set. 2019. 
RIBEIRO, Disneylândia Maria. Barreiras atitudinais: obstáculos e desafios à inclusão de estudantes com deficiência no ensino superior. Curitiba: CRV, 2018.

RODRIGUES, David. A inclusão na universidade: limites e possibilidades da construção de uma Universidade Inclusiva. Revista Educação Especial, n. 23, 2004. Disponível em:

https://periodicos.ufsm.br/educacaoespecial/article/view/4951/2980 Acesso em: 25 set. 2019.

SANTOS, Mônica Pereira dos; FONSECA, Michele Pereira de Souza da. Concepções de docentes e licenciandos de educação física acerca de inclusão em educação: perspectiva omnilética em discussão. Interacções, n. 23, p. 128-145, 2013.

\section{Como referenciar este artigo}

LUSTOSA, F. G.; RIBEIRO, D. M. Inclusão de estudantes com deficiência no ensino superior: exigências de reconfiguração de saberes, concepções e práticas docentes. Revista Ibero-Americana de Estudos em Educação, Araraquara, v. 15, n. esp. 2, p. 1523-1537, ago. 2020. e-ISSN: 1982-5587. DOI: https://doi.org/10.21723/riaee.v15iesp2.13825

Submetido em: 30/08/2019

Revisões requeridas: $30 / 11 / 2019$

Aprovado em: 02/02/2020

Publicado em: 01/08/2020 